\title{
Effect of Race and Sex on Primary Care Physicians' Diagnosis and Treatment of Late-Life Depression
}

\author{
Helen C. Kales, MD, ${ }^{* \dagger}$ Harold W. Neighbors, $P h D,{ }^{\mathcal{S}}$ Marcia Valenstein, MD, MS, ${ }^{* \neq}$ \\ Frederic C. Blow, PhD, ${ }^{* \neq}$ John F. McCarthy, PhD, ${ }^{* \ddagger}$ Rosalinda V. Ignacio, MS, ${ }^{* \neq}$ \\ Kiran K.-K. Taylor, MD, ${ }^{\ddagger}$ Leah Gillon, MSW, ${ }^{*}$ and Alan M. Mellow, MD, PhD ${ }^{\ddagger}$
}

OBJECTIVES: To examine primary care physician (PCP) contributions toward racial and sex differences in the diagnosis and treatment of late-life depression.

DESIGN: Survey using a computerized instrument incorporating video interviews and text, with volunteer PCPs randomly assigned to one of four standardized video vignettes of an elderly patient depicting late-life depression. Vignettes differed only in the patient/actor's race (white/ African-American) or sex.

SETTING: American Academy of Family Physicians meeting, San Diego, California, 2002.

PARTICIPANTS: One hundred seventy-eight U.S.-practicing postresidency PCPs who were asked to participate in a clinical decision-making study.

MEASUREMENTS: The computerized survey instrument assessed PCPs' diagnoses, first-line treatment and management recommendations, and judgment of personal characteristics/behaviors for the patients in the vignettes.

RESULTS: Eighty-five percent of all PCPs correctly diagnosed the elderly patient(s) with major depression. There were no significant differences in the diagnosis of depression, treatment recommendations, or PCP assessment of most patient characteristics by the race or sex of the patient/ actor in the vignette, but PCP characteristics, most notably

From the * Serious Mental Illness Treatment Research Education and Clinical Center, Health Services Research and Development, ${ }^{\dagger}$ Geriatric Research Education and Clinical Center, Veterans Affairs Ann Arbor Healthcare System, Ann Arbor, Michigan; ${ }^{\ddagger}$ Department of Psychiatry and ${ }^{\S}$ Department of Health Behavior/Health Education, School of Public Health, University of Michigan, Ann Arbor, Michigan; and "VISN 11 Mental Health Service Line, Department of Veterans Affairs, Ann Arbor, Michigan.

Research was supported by a Health Services Research and Development Research Career Development Award from the Department of Veterans Affairs and an unrestricted grant from the Blue Cross Blue Shield Foundation of Michigan.

Presented in part at the American Association for Geriatric Psychiatry 17th Annual Meeting, Baltimore, Maryland, February 21-24, 2004, and at the Veterans Affairs Health Services Research and Development National Meeting, Washington, DC, March 9-11, 2004.

Address correspondence to Helen C. Kales, MD, Psychiatry Service (116 A), VAMC, 2215 Fuller Road, Ann Arbor, MI, 48105. E-mail: kales@umich.edu DOI: $10.1111 / \mathrm{j} .1532-5415.2005 .53255 . \mathrm{x}$ the location of medical school training (U.S. vs international), affected the likelihood of a depression diagnosis and treatment recommendations.

CONCLUSION: Given standardized symptom-pictures, PCPs are just as likely to diagnose and treat depression in African-American as in white older people, suggesting that bias based simply on apparent patient race is not a likely explanation for the lower rates of depression diagnosis and treatment in older African Americans. PCPs who have trained at international medical schools may benefit from targeted training initiatives on the diagnosis and treatment of late-life depression. J Am Geriatr Soc 53:777-784, 2005.

Key words: African Americans; older adults; mental health in primary care; geriatric; elderly

$M$ ajor depression causes significant morbidity and may contribute to mortality in late life, ${ }^{1}$ but studies indicate that late-life depression continues to be underdiagnosed and undertreated. ${ }^{2-4}$ Few older adults with depression receive mental health services; instead they are usually treated in primary care settings. Medical and neuropsychiatric comorbidities complicate accurate diagnosis and treatment of late-life depression. ${ }^{5}$ Such factors as the patient's race or sex may also affect diagnosis and treatment decisions. Many studies report lower rates of depression diagnoses (and higher rates of psychotic diagnoses) in African Americans than in whites in psychiatric settings. ${ }^{6-10}$ The few studies that have examined racial differences in diagnostic rates in older adults report similar results. ${ }^{11-14}$ Older African Americans in the community may also be less likely to use antidepressants than older white people. ${ }^{15}$

Fewer studies have examined racial and sex variation in depression treatment in primary care. Elderly patients, men, and African Americans are more likely to see primary care physicians (PCPs) than psychiatrists for mental health treatment. ${ }^{16}$ As a result, it is particularly important to assess potential disparities in the diagnosis and treatment of depression in primary care settings. One study found that 
PCPs were less likely to counsel African-American than white patients for depression, ${ }^{17}$ although this difference resolved after adjusting for patients' education level and socioeconomic status (SES). Another study found that African Americans were less likely than whites to find antidepressant medication acceptable. ${ }^{18}$ In primary care settings, older women have higher rates of depression diagnosis and treatment than older men, ${ }^{19}$ but a recent study found that neither depression diagnosis nor antidepressant treatment recommendations by PCPs were associated with patient age, race, sex, or SES. ${ }^{20}$

Although differences in rates of clinical diagnosis and treatment of depression by race have been frequently found in mixed-age and elderly samples, few studies have evaluated why these differences are found. Differences in rates of diagnosis and treatment may reflect a multitude of factors, but misdiagnosis and clinician bias are the most frequently cited possible etiological factors, ${ }^{8-10,21-24}$ although the evidence is limited ${ }^{25}$ and often indirect. ${ }^{23,24}$

Although it is hazardous to infer bias solely from the existence of health disparities, ${ }^{25}$ this inference has been made repeatedly, largely based upon the cross-classification of race and the diagnosis of psychotic/mood disorders. ${ }^{26}$ Racial bias involves making unwarranted judgments about people on the basis of their race. ${ }^{25}$ Although race is most simply associated with an individual's skin color and physical characteristics, it may also act as a proxy for culturally mediated beliefs, values, and communication styles as well as become confounded with the effects of SES. In the extreme, clinician bias assumes that, given the same set of symptoms, clinicians unconsciously assign a certain diagnosis based upon a patient's skin color and associated physical characteristics (e.g., assigning an African-American patient a psychotic disorder diagnosis and a white patient an affective disorder diagnosis).

The potential effect of racially based bias on the diagnosis and treatment of depression may be even more critical in the elderly, in whom depression management is already complex because of medical illness and neuropsychiatric comorbidity. Potential mismanagement of a mood disorder as a psychotic disorder in an elderly minority patient could lead to poor outcomes and side effects such as tardive dyskinesia. Tardive dyskinesia is more common in AfricanAmerican patients ${ }^{27}$ and could be a direct consequence of the misdiagnosis and management of a mood disorder as a psychotic disorder. Evaluating whether PCPs contribute to mental health disparities may inform efforts to improve the diagnosis and treatment of late-life depression in specific patient subgroups.

The Surgeon General's report on mental health disparities $^{28}$ notes that the role of clinician bias in racial differences in the diagnosis of mental disorders remains a complex issue demanding a series of innovative research studies. As a first step toward investigating the role of physician bias in racial disparities in the diagnosis and treatment of late-life depression in primary care settings, a controlled experiment was conducted that standardized patient presentation and symptom report. It was hypothesized that patient race (as indicated to participants by skin color, facial features, and speech style) and sex would influence PCPs' diagnosis and management recommendations.

\section{METHODS}

\section{Survey Instrument}

Similar to a previous study examining the effects of race and sex on treatment recommendations in cardiology, ${ }^{29} \mathrm{a}$ computerized survey instrument was developed that incorporated video recorded interviews of elderly patients with symptoms of major depression. The computerized survey was designed to record PCPs' demographic characteristics, assess PCPs' diagnosis and management recommendations for the patients in the vignettes, and examine PCPs' judgment of patient characteristics.

The 5-minute video consisted of a scripted interview with a patient/actor. Four board-certified geriatric psychiatrists (HCK, AMM, SMM, BAK) wrote and reviewed the script for major depression. Established Diagnostic and Statistical Manual of Mental Disorders, Fourth Edition (DSM-IV) criteria for major depression ${ }^{30}$ were met, but the script was also created with the frequent medical and neuropsychiatric complexity of late-life depression in mind. ${ }^{5}$ The effect of race on interpretations of behavior also may be exacerbated when behavior is ambiguous or open to multiple interpretations. ${ }^{31}$ Therefore, the script included the ambiguity often present in clinical situations, with other symptoms such as cognitive problems, alcohol use, and paranoia accompanying symptoms of depression. The written vignette was piloted individually with two board-certified psychiatrists (blind to the purpose of the study), both of whom diagnosed the patient with major depression.

To represent the possible combinations of race and sex, four actors were recruited to portray the patients in the vignettes (Figure 1). As in the Schulman et al. study, actors were used because they were considered better able than patients to read the scripts verbatim and to express consistent affect across vignettes. Vignettes were recorded at a single studio (Russell Video Services, Ann Arbor, MI) and produced by ImageWeaver Studios (Ann Arbor, MI), a company with expertise in educational medical video production. Actors followed identical scripts and direction, dressed in similar clothing, and displayed the same affect within video segments. The four video vignettes (white female (WF), white male (WM), African-American female

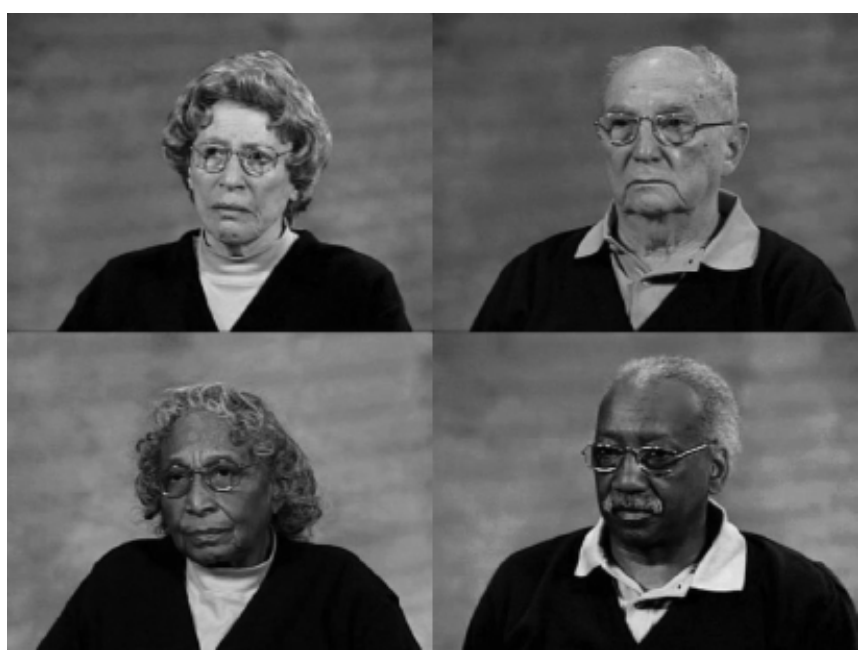

Figure 1. Patients as portrayed by actors in the video portion of survey. 
(AF), and African-American male (AM)) were each piloted separately with at least two additional board-certified psychiatrists (12 psychiatrists in total) who were blind to the purpose of the study. The rate of agreement on diagnosis across all observers was $93 \%$.

A computer screen that listed the patient's age (73), medical conditions (diabetes mellitus, arthritis, and hypertension), insurance status (Medicare and Blue Cross Blue Shield supplemental insurance), and information that his or her daughter brought the patient in introduced the video patient interview segment. To assess decisions about diagnosis, PCPs were asked to choose the single-best DSM-IV diagnosis for the patient based on the information from the video. Choices included major depression, dementia, delusional disorder, schizophrenia, and alcohol abuse. They were then asked their degree of certainty in their primary diagnosis. PCPs were also presented with a list of possible treatment choices and asked to select their preferred initial treatment for the patient. They were surveyed about how long they would follow the patient, when they would consider referring the patient to a psychiatrist, and the one piece of additional information (e.g., head computed tomography scan, medical history, Mini-Mental State Examination (MMSE) score, substance history) they would want to make a more certain diagnosis and formulate treatment recommendations.

The final portion of the survey involved PCPs' judgment about patient characteristics (modified from the Schulman et al. survey; Schulman KA, personal communication). Patient characteristics included patient attributes (demeanor toward the examiner and SES) and predicted behaviors (complying with and benefiting from treatment, forming an alliance with the physician, understanding recommendations, and likelihood of experiencing side effects).

Viewing the vignette and answering the survey took approximately 10 minutes. The software program required viewing the entire vignette before answering survey questions and presentation of all components of the survey instrument before completion.

\section{Study Subjects and Data Collection}

PCP subjects were participants at the 2002 American Academy of Family Physicians Annual Meeting in San Diego, California. PCPs were recruited on site; those completing the study received a calculator as remuneration. PCP participants were told that they were taking part in a study of clinical decision-making involving mental health issues in primary care, but they were not told that the primary purpose of the study was to assess the effect of race and sex on the diagnosis and treatment of late-life depression.

Surveys were administered in a main meeting exhibit hall booth that had six individual computer stations. The layout was designed to provide the participants privacy and prevent them from viewing each other's video interviews/ surveys. The PCPs were randomly assigned to view one of the four vignettes.

\section{Sample Size}

Based upon prior differences found for rates of clinical depression diagnoses in older people by race (19\% diagnosed mood disorders in whites and $8 \%$ in African Americans), ${ }^{14}$ the required sample size was estimated based on an ability to detect a medium effect size. ${ }^{32}$ Using an alpha level of $0.05,40$ participants per group ensured a power of $97 \%$ to detect main effects for race group and sex group.

\section{Statistical Analysis}

PCPs' diagnostic assessments, management recommendations, and judgments of patient characteristics based on the randomly assigned video vignettes were examined using the following analyses. First, univariate (mean, standard deviation) and bivariate (Spearman and Pearson correlations) descriptive statistics were calculated overall and by vignette. Chi-square $\left(\chi^{2}\right)$ tests were used to examine differences in categorical variables. One-way analysis of variance was used to examine group differences in continuous outcome measures. Tukey's Honestly Significant Differences procedure for correction of multiple comparisons was used to test post hoc differences between vignettes. For all analyses, alpha was set at 0.05 , and all tests were two-sided.

Logistic regression analyses were conducted to assess the effects of PCP characteristics on diagnosis and treatment recommendations, controlling for patient race and sex. PCP characteristics used as predictors were age, sex, race, medical school location (U.S. vs international), practice location, board certification, and years since graduation. Physician race was dichotomized as white versus nonwhite rather than using several racial categories because of the small numbers $(6.2 \%)$ of African-American PCPs. Separate logistic regression models were estimated for each PCP characteristic because of the high multicollinearity between the predictors.

\section{RESULTS}

One hundred seventy-eight PCPs volunteered to participate in the study. These subjects were randomly assigned to each patient vignette and did not differ significantly on any PCP characteristics (Table 1).

\section{Primary Diagnosis}

Eighty-five percent $(\mathrm{n}=151)$ of PCPs diagnosed the elderly patient as having major depression as the primary diagnosis. Analysis of provider diagnosis by vignette viewed showed the following percentages of a diagnosis of major depression: $\mathrm{WF}=79.6 \%(\mathrm{n}=35), \mathrm{WM}=80.4 \%(\mathrm{n}=37), \mathrm{AF}=87.0 \%$ $(\mathrm{n}=40)$, and $\mathrm{AM}=92.9 \%(\mathrm{n}=39)\left(\chi^{2}=3.91\right.$, degrees of freedom $(d f)=3, P=.27)$. The other psychiatric diagnoses chosen by PCPs included dementia, delusional disorder, and schizophrenia. Follow-up comparisons indicated that the AM was no more likely to receive a diagnosis of depression than the WF, WM, or AF $(95 \%$ confidence interval $(\mathrm{CI})=0.08-1.19,0.08-1.26$, and $0.12-2.20$, respectively).

\section{Level of Certainty in Diagnosis}

Of PCPs choosing a diagnosis of major depression $(n=151)$, there were significant differences in mean level of certainty (rated as $0-100 \%$ ) in this diagnosis by vignette viewed $(\mathrm{WF}=71.0 \%, \mathrm{WM}=66.9 \%, \mathrm{AF}=80.4 \%, \mathrm{AM}=$ $72.2 \% ; \mathrm{F}=4.15, d f=3,147, P<.001)$. Post hoc analyses revealed that the mean level of certainty rated by PCPs for 
Table 1. Characteristics of the Primary Care Physicians (PCPs) According to Race and Sex of Patient

\begin{tabular}{|c|c|c|c|c|c|c|}
\hline \multirow[b]{2}{*}{ Characteristic } & \multicolumn{2}{|c|}{ White } & \multicolumn{2}{|c|}{ African-American } & \multirow[b]{2}{*}{ Significance Test } & \multirow[b]{2}{*}{$P$-value } \\
\hline & Female & Male & Female & Male & & \\
\hline PCPs, n & 44 & 46 & 46 & 42 & & \\
\hline Age, mean & 42.3 & 41.8 & 46.6 & 43.0 & $F=0.67_{(3,170)}$ & .57 \\
\hline Years since medical school graduation, mean & 19.9 & 19.0 & 20.2 & 21.9 & $F=0.46_{(3,171)}$ & .71 \\
\hline Male, n (\%) & $32(72.7)$ & $32(69.6)$ & $32(69.6)$ & $29(69.0)$ & $\chi^{2}=0.18$ & .98 \\
\hline White, n (\%) & $30(68.2)$ & $33(71.7)$ & $36(78.3)$ & $27(64.3)$ & $\chi^{2}=2.27_{(3)}$ & .52 \\
\hline U.S. medical school location, n (\%) & $36(81.8)$ & $36(78.3)$ & $35(76.1)$ & $31(73.8)$ & $\chi^{2}=0.87_{(3)}$ & .83 \\
\hline Board certified, n (\%) & $42(95.4)$ & $41(89.1)$ & $44(95.6)$ & $35(83.3)$ & $\chi^{2}=5.50_{(3)}$ & .14 \\
\hline Urban practice location, $n(\%)$ & $23(52.3)$ & $18(39.1)$ & $24(52.2)$ & $17(40.5)$ & $\chi^{2}=2.79_{(3)}$ & .43 \\
\hline
\end{tabular}

the AF was significantly higher than that rated for the WM $(P<.05)$.

\section{Management Recommendations}

PCPs did not differ in their treatment recommendations for the patient viewed. The majority of PCPs chose an antidepressant as their first-line treatment. By vignette viewed, the percentage of PCPs choosing any antidepressant was $\mathrm{WF}=81.8 \%(\mathrm{n}=36), \mathrm{WM}=89.1 \%(\mathrm{n}=41), \mathrm{AF}=89.1 \%$ $(\mathrm{n}=41)$, and $\mathrm{AM}=90.5 \% \quad(\mathrm{n}=38) \quad\left(\chi^{2}=1.88, \quad d f=3\right.$, $P=.60)$. Most PCPs chose newer antidepressant agents (e.g., selective serotonin reuptake inhibitors) as their first-line treatment; by vignette viewed, the percentage of PCPs choosing newer antidepressants was $\mathrm{WF}=77.3 \% \quad(\mathrm{n}=34)$, $\mathrm{WM}=89.1 \%(\mathrm{n}=41), \mathrm{AF}=87.0 \%(\mathrm{n}=40)$, and $\mathrm{AM}=$ $85.7 \%(\mathrm{n}=36)\left(\chi^{2}=2.80, d f=3, P=.42\right)$.

Across vignettes, the top three follow-up choices were follow up for more than 6 months, follow up for 1 to 3 months, and referral to a non-medical doctor mental health provider (e.g., psychologist, social worker) (Table 2). Collapsing the follow-up choices into follow-up for more than 6 months versus other, it was found that there were no significant differences by vignette viewed as indicated by PCPs $\left(\chi^{2}=5.14, d f=3, P=.16\right)$.

PCPs' choices regarding potential psychiatric referral also did not differ by vignette viewed. Across vignettes, the most common response, given by $57.3 \%(\mathrm{n}=102)$ of the PCPs, was that they would refer the patient to a psychiatrist "if there was a poor treatment response after 1 to 3 months," followed by $24.2 \%(n=43)$ referring for poor response after 4 to 6 months, and $8.4 \%(n=15)$ referring for a poor response after more than 6 months. Approximately $5.6 \%(\mathrm{n}=10)$ of the PCPs responded that they would refer immediately after the evaluation, and $4.5 \%$ $(\mathrm{n}=8)$ responded that they would never refer.

PCPs also indicated that the single piece of additional information they would most like regarding the patient was a full medical history and laboratory test information $(\mathrm{WF}=40.9 \% \quad(\mathrm{n}=18), \mathrm{WM}=39.1 \% \quad(\mathrm{n}=18)$, $\mathrm{AF}=52.2 \% \quad(\mathrm{n}=24), \mathrm{AM}=57.1 \% \quad(\mathrm{n}=24))$, followed by MMSE ( WF $=47.7 \%(\mathrm{n}=21), \mathrm{WM}=52.2 \%(\mathrm{n}=24)$, $\mathrm{AF}=43.5 \%(\mathrm{n}=20), \mathrm{AM}=31.0 \%(\mathrm{n}=13))$. Other additional information chosen by PCPs included full substance abuse history and head computed tomography. Collapsing the choices into full medical history and laboratory work versus other, the PCPs did not differ significantly by vignette viewed $\left(\chi^{2}=4.02, d f=3, P=.26\right)$.

\section{PCP Assessment of Patient Characteristics}

PCPs were asked to assess two personal attributes of the patient and five predicted patient behaviors. These assessments did not differ by the race or sex of the patient (Table 3 ) with the exception of estimates of the patient's SES. Notably, PCPs did not judge African-American patients as any less likely to adhere to or benefit from treatment. With regard to SES, both the WF and WM patients were rated as

Table 2. Follow-Up Choices Indicated by Primary Care Physicians (PCPs) by Vignette Viewed

\begin{tabular}{|c|c|c|c|c|}
\hline \multirow[b]{2}{*}{ Follow-Up Choice } & \multicolumn{2}{|c|}{ White } & \multicolumn{2}{|c|}{ African-American } \\
\hline & Female & Male & Female & Male \\
\hline PCPs, $n$ & 44 & 46 & 46 & 42 \\
\hline No further treatment, $\mathrm{n}(\%)$ & $0(0.0)$ & $0(0.0)$ & $0(0.0)$ & $1(2.4)$ \\
\hline Referral to psychiatrist, $\mathrm{n}(\%)$ & $1(2.3)$ & $3(6.5)$ & $3(6.5)$ & $1(2.4)$ \\
\hline Referral to a non-medical doctor mental health provider, $\mathrm{n}(\%)$ & $3(6.8)$ & $6(13.0)$ & $4(8.7)$ & $7(16.7)$ \\
\hline Referral to another specialist, $\mathrm{n}(\%)$ & $0(0.0)$ & $2(4.4)$ & $1(2.2)$ & $0(0.0)$ \\
\hline \multicolumn{5}{|l|}{ Follow-up, months, $n(\%)$} \\
\hline $1-3$ & $15(34.1)$ & $16(34.8)$ & $19(41.3)$ & $12(28.6)$ \\
\hline $4-6$ & $3(6.8)$ & $6(13.0)$ & $2(4.4)$ & $2(4.8)$ \\
\hline$>6$ & $22(50.0)$ & $13(28.3)$ & $17(37.0)$ & $19(45.2)$ \\
\hline
\end{tabular}

$\mathrm{F}=17.82_{(18)}, P=.47$. 
Table 3. Primary Care Physician (PCP) Assessments of Patient Characteristics by Vignette Viewed

\begin{tabular}{|c|c|c|c|c|c|c|}
\hline \multirow[b]{3}{*}{ Characteristic } & \multicolumn{2}{|c|}{ White } & \multicolumn{2}{|c|}{ African-American } & \multirow[b]{3}{*}{$\mathrm{F}$} & \multirow[b]{3}{*}{$P$-value } \\
\hline & Female & Male & Female & Male & & \\
\hline & \multicolumn{4}{|c|}{ Mean \pm Standard Deviation } & & \\
\hline Demeanor* & $34.0 \pm 11.4$ & $32.6 \pm 9.8$ & $37.1 \pm 13.2$ & $36.4 \pm 11.8$ & $1.40_{(3,174)}$ & .25 \\
\hline Socioeconomic status ${ }^{\dagger}$ & $48.5 \pm 16.6$ & $50.9 \pm 13.1$ & $38.3 \pm 16.7$ & $41.0 \pm 15.9$ & $6.59_{(3.174)}$ & $<.001 \S$ \\
\hline \multicolumn{7}{|c|}{ Individual assessment of predicted behavior } \\
\hline Likely to comply with treatment & $50.3 \pm 20.1$ & $52.7 \pm 20.5$ & $48.5 \pm 20.6$ & $51.7 \pm 19.8$ & $0.36_{(3,174)}$ & .78 \\
\hline Likely to benefit from treatment & $76.4 \pm 16.6$ & $77.1 \pm 14.0$ & $78.1 \pm 15.3$ & $77.2 \pm 15.7$ & $0.08_{(3,174)}$ & .97 \\
\hline Likely to form a treatment alliance & $70.6 \pm 19.5$ & $73.8 \pm 19.4$ & $73.1 \pm 19.0$ & $75.5 \pm 16.7$ & $0.51_{(3,174)}$ & .67 \\
\hline Likely to understand recommendations & $53.3 \pm 23.5$ & $54.8 \pm 22.0$ & $57.9 \pm 21.1$ & $59.8 \pm 20.0$ & $0.81_{(3,174)}$ & .49 \\
\hline Likely to have side effects & $57.3 \pm 23.1$ & $53.7 \pm 19.2$ & $54.3 \pm 17.3$ & $49.0 \pm 20.4$ & $1.23_{(3,174)}$ & .30 \\
\hline
\end{tabular}

${ }^{*} 0=$ hostile, $100=$ friendly.

${ }^{\dagger} 0=$ low, $100=$ high.

${ }^{\ddagger} 0=$ very unlikely, $100=$ very likely.

${ }^{\S}$ Post hoc comparisons: white female $\gg$ African-American female; white male $\gg$ African-American female and African-American male, $P<.05$.

being of significantly higher SES than the AF patient, and the WM was rated as being of significantly higher SES than the AM patient (Tukey's post hoc comparison, $P<.05$ ). Given the differences between vignettes found for SES, additional analyses were performed using SES as a covariate. PCPs' estimates of SES did not affect their choice of diagnosis.

\section{Analyses Using PCP Characteristics}

Associations between PCP characteristics and the diagnosis of major depression, treatment, and management recommendations are presented in Table 4. Of PCP characteristics, location of medical school training, PCP race, and board certification were associated with effects on diagnosis and management recommendations. PCP sex, time since graduation, and practice location did not influence diagnosis/recommendations.

Overall, $77.5 \%(\mathrm{n}=138)$ of the total sample were U.S. medical graduates (USMGs), whereas $22.5 \%(\mathrm{n}=40)$ were international medical graduates (IMGs). The overall racial breakdown of the PCPs was as follows: white $=70.8 \%$ $(\mathrm{n}=126), \quad$ Asian $=18.5 \% \quad(\mathrm{n}=33), \quad$ African-American $=6.2 \%(\mathrm{n}=11)$, Hispanic $=3.4 \% \quad(\mathrm{n}=6)$, and other $=1.1 \% \quad(n=2)$. Ninety-one percent $(n=162)$ of the PCPs in the sample were board certified.

IMGs were significantly less likely than USMGs to diagnose depression, choose newer antidepressants as first-line

Table 4. Effect of Primary Care Physician (PCP) Characteristics on Diagnosis, Treatment, and Follow-Up Recommendations

\begin{tabular}{|c|c|c|c|c|c|c|c|c|c|}
\hline PCP Trait & $\begin{array}{c}\text { Depression } \\
\text { Diagnosis } \\
\mathrm{n}(\%)\end{array}$ & $\begin{array}{l}\text { Chi- } \\
\text { Square }\end{array}$ & $P$-value & $\begin{array}{c}\text { Newer } \\
\text { Antidepressant } \\
\mathrm{n}(\%)\end{array}$ & $\begin{array}{l}\text { Chi- } \\
\text { Square }\end{array}$ & $P$-value & $\begin{array}{l}\text { Long-Term } \\
\text { Follow-Up } \\
\mathrm{n}(\%)\end{array}$ & $\begin{array}{l}\text { Chi- } \\
\text { Square }\end{array}$ & $P$-value \\
\hline U.S. medical school graduate & & $6.10_{(1)}$ & .01 & & $3.88_{(1)}$ & .049 & & $8.51_{(1)}$ & $<.001$ \\
\hline Yes & $122(88.4)$ & & & $121(87.7)$ & & & $63(45.6)$ & & \\
\hline No & $29(72.5)$ & & & $30(75.0)$ & & & $8(20.0)$ & & \\
\hline White & & $13.89_{(1)}$ & $<.001$ & & $3.57_{(1)}$ & .06 & & $13.07_{(1)}$ & $<.001$ \\
\hline Yes & $115(91.3)$ & & & $111(88.1)$ & & & $61(48.4)$ & & \\
\hline No & $36(69.2)$ & & & 40 (76.9) & & & $10(19.2)$ & & \\
\hline Male & & $0.22_{(1)}$ & .64 & & $0.87_{(1)}$ & .35 & & $0.51_{(1)}$ & .47 \\
\hline Yes & $105(84.0)$ & & & $104(83.2)$ & & & $52(41.6)$ & & \\
\hline No & $46(86.8)$ & & & $47(88.7)$ & & & $19(35.8)$ & & \\
\hline $\begin{array}{l}>10 \text { years since medical } \\
\text { school graduation }\end{array}$ & & $1.11_{(1)}$ & .29 & & $2.43_{(1)}$ & .12 & & $1.73_{(1)}$ & .19 \\
\hline Yes & $120(86.3)$ & & & $121(87.1)$ & & & $59(42.4)$ & & \\
\hline No & $31(79.5)$ & & & $30(76.9)$ & & & $12(30.8)$ & & \\
\hline Board certified & & $1.32_{(1)}$ & .25 & & $6.81_{(1)}$ & .009 & & $3.28_{(1)}$ & .07 \\
\hline Yes & $139(85.8)$ & & & $141(87.0)$ & & & $68(42.0)$ & & \\
\hline No & $12(75.0)$ & & & $10(62.5)$ & & & $3(18.8)$ & & \\
\hline Urban practice location & & $1.15_{(1)}$ & .28 & & $0.43_{(1)}$ & .51 & & $1.30_{(1)}$ & .26 \\
\hline Yes & 67 (81.7) & & & 68 (82.9) & & & $29(35.4)$ & & \\
\hline No & $84(87.5)$ & & & $83(86.5)$ & & & $42(43.8)$ & & \\
\hline
\end{tabular}


treatment, and recommend follow-up for longer than 6 months for the older patients. Additionally, in assessment of patient characteristics, IMGs rated the AM patient as being of significantly lower SES than did USMGs $\left(\mathrm{t}_{40}=-2.33\right.$, $P=.03)$. Nonwhite PCPs were significantly less likely than white PCPs to diagnose depression and recommend longterm follow-up. There was also a trend for nonwhite PCPs to be less likely to choose newer antidepressants as initial treatment. Nonwhite PCPs were also significantly less likely to think that the WM patient would benefit from treatment $\left(\mathrm{t}_{44}=-2.14, P=.04\right)$ or form a physician-patient alliance $\left(t_{44}=-3.04, P<.001\right)$ than did white PCPs. Board-certified PCPs were significantly more likely than non-board certified PCPs to recommend treatment with newer antidepressants and more likely to recommend long-term followup (trend-level). There were no differences in the diagnosis or management of depression based upon patient race and sex found in IMG, nonwhite, or non-board certified PCPs.

\section{Post Hoc Analyses of PCP Characteristics}

Separate logistic regression models were computed for each PCP trait, with patient race and sex included as predictor variables. The results for diagnosis indicated that only medical school location $(P=.01)$ and PCP race $(P<.001)$ affected diagnosis; medical school location and PCP race were found to be significantly correlated (coefficient of determination $\left.\left(r^{2}\right)=0.48, P<.001\right)$. IMGs were significantly less likely to choose depression as a diagnosis than USMGs (odds ratio $(\mathrm{OR})=3.24,95 \% \mathrm{CI}=1.32-7.93$ ). Nonwhite PCPs were significantly less likely to choose depression as a diagnosis than white PCPs $(\mathrm{OR}=4.83,95 \% \mathrm{CI}=2.02-$ 11.54). Physician sex, years since medical school graduation, board certification, and practice location did not predict diagnosis.

Medical school location $(P=.04)$ and board certification $(P<.001)$ significantly predicted prescription of newer antidepressants; U.S. medical school location was found to be significantly correlated with board certification $\left(r^{2}=0.25, P<.001\right)$. IMGs were significantly less likely to recommend newer antidepressants than USMGs $(\mathrm{OR}=$ $2.50,95 \% \mathrm{CI}=1.03-6.07)$. Non-board certified PCPs were also significantly less likely to choose newer antidepressants than board-certified PCPs $(\mathrm{OR}=5.16,95 \%$ $\mathrm{CI}=1.59-16.78)$. Physician sex, race, years since medical school graduation, and practice location did not predict prescription of newer antidepressants.

Given the findings that medical school location and race were highly correlated and significantly associated with correct diagnosis, these variables were further analyzed. For USMGs $(\mathrm{n}=138)$, racial identification was as follows: $82.6 \%(\mathrm{n}=114)$ white, $8.0 \%(\mathrm{n}=11)$ AfricanAmerican, 5.8\% (n=8) Asian, 2.9\% (n=4) Hispanic, and $0.7 \%(n=1)$ other. For IMGs $(n=40)$, racial identification was $30.0 \%(\mathrm{n}=12)$ white, $0 \%(\mathrm{n}=0)$ AfricanAmerican, 62.5\% $(\mathrm{n}=25)$ Asian, 5.0\% $(\mathrm{n}=2)$ Hispanic, and $2.5 \%(n=1)$ other. Of the 40 IMGs, $32.5 \%(n=13)$ were from the Philippines, $17.5 \%(\mathrm{n}=7)$ from India or Pakistan, $12.5 \%(\mathrm{n}=5)$ from Mexico or South America, $7.5 \%(n=3)$ from Canada, $7.5 \%(n=3)$ from the West Indies/Caribbean, and 2.5\% $(\mathrm{n}=1)$ from Syria, Vietnam, Myanmar (formerly Burma), Thailand, and Japan. Ten per- cent $(n=4)$ were missing a medical school location. Of the 52 nonwhite physicians in the sample, 53.8\% $(\mathrm{n}=28)$ trained overseas.

Finally, in terms of PCP race, the percentage of PCPpatient pairs that were racially matched (white patient/ white PCP or African-American patient/African-American PCP) were assessed; $38.2 \%(n=68)$ of pairs were so matched, but this racial matching did not correlate with correct diagnosis or treatment.

\section{DISCUSSION}

These findings suggest that PCP bias based simply on patient skin color (as well as other characteristics associated with race such as facial features and speech style) is not a likely explanation for the lower rates of clinical depression diagnoses in African Americans seen in primary care settings. Although two case series of older African-American patients (veterans in a long-term psychiatric facility ${ }^{23}$ and patients referred to a community mental health center ${ }^{24}$ ) suggested misdiagnosis, sample size and questions as to whether the misdiagnosis was based upon patients' race or other factors limited these studies. The latter may include nonracially based misdiagnoses that may have been more prevalent before the DSM-III era. The current experimental findings are concordant with a recent study that found that neither race nor sex significantly affected rates of depression diagnoses or treatment in primary care settings. ${ }^{20}$

In clinical settings, race-associated disparities in depression diagnosis and treatment patterns may result from patient-level factors other than race as divined from a patient's appearance. These factors may include different symptom presentations of depression, lower usage of formal healthcare settings for treatment of elderly African Americans, and patient treatment preferences. Prior findings that mixed-age African-American patients with depression had higher ratings of hostility and irritability and a greater frequency of somatic complaints suggest the first. ${ }^{33}$ Studies demonstrating different patterns of help-seeking and healthcare utilization for depression of African Americans, including more reliance on informal support (friends, ministers, etc.) for emotional problems, indicate the second. ${ }^{34,35}$ A recent study finding that PCPs recognized depression and recommended treatment for AfricanAmerican patients as often as for white patients but that African-American patients were significantly less likely to accept antidepressant medications supports the third. ${ }^{36}$ Differential symptom presentations, patterns of treatmentseeking, and treatment preferences by race may have affected prior studies finding lower rates of clinical depression diagnoses and treatment in elderly African Americans. Similarly, patient-level factors may also have affected prior studies finding lower rates of depression in men, with men seeking depression treatment at lower rates, ${ }^{37}$ being less likely to recognize their depressive symptoms, ${ }^{38}$ and being less likely to initiate discussions with providers about depression than women. ${ }^{39}$ This study's design standardized patient presentations to isolate physician decision-making to examine the question of whether a patient's apparent race or sex affected diagnostic and treatment decisions. With standardized vignettes, PCPs did not express greater uncertainty when making a diagnosis of major depression 
for the minority patients. Indeed, the mean level of certainty of the depression diagnosis was significantly higher for the African-American female patient than the white male patient. This finding may reflect PCPs acknowledging the higher reported rates of depression in women and a possibly heightened sensitivity to the concern of underdiagnosis of depression in African-American patients given cultural competency efforts.

PCPs' estimates of SES appeared to be dissociated from their assignments of diagnoses by vignette viewed. PCPs' estimates of SES may have been based upon known population differences in income as opposed to racial bias. Another possibility is that PCPs' estimates of SES may have been racially based but that this bias was not associated with different diagnostic impressions.

Although there was a lack of overall effects of patient race and sex on PCP decision-making, it was found that certain characteristics of the PCPs themselves affected depression diagnosis and treatment recommendations. The two factors that appeared to have the largest effect upon the main study questions were PCP location of medical school training and race. These factors were highly correlated with each other; $70 \%$ of IMGs were nonwhite, and $54 \%$ of nonwhite physicians were trained overseas.

Although there were no significant differences by patient race or sex between IMG and nonwhite PCPs for the diagnosis and treatment of depression, several of the assessments of patient characteristics pointed to possible influences of patient race and sex. IMG PCPs rated the African-American male patient as being of lower SES than did USMGs. Nonwhite PCPs also rated the white male patient as significantly less likely to benefit from treatment and less able to form a physician-patient alliance than white PCPs. These findings may reflect cultural differences within the PCP/patient dyad.

Although physician influence on racial disparities is often thought of as involving a white physician and a nonwhite patient, it is also important to consider other possible dyadic relationships (e.g., Asian physician/white patient). Patient-provider race/ethnicity concordance has been found to be positively associated with treatment outcomes, ${ }^{40}$ but these analyses indicated that, in racially matched PCP/patient pairs, there was no correlation with correct diagnosis and treatment of depression.

There is limited research examining the effects of having received medical training outside the United States on health disparities. One study found that before and after PCP home care training seminars, IMG physicians were significantly less likely to make home visits for older patients than U.S.-trained physicians. ${ }^{41}$ These authors speculated that IMG PCPs may not have had prior training with or exposure to such services. Similarly, in this study, the IMG PCPs may have had less familiarity with depressive syndromes. A recent study ${ }^{42}$ that surveyed PCPs found that providers' previous treatment experiences, such as having had older patients who responded to antidepressant treatment, and their beliefs about the effectiveness of antidepressant treatments largely influenced the decision to treat older patients with antidepressants. Many countries report a lower prevalence of depression than does the United States, potentially secondary to decreased reporting of mental disorders, disorders that are often accompanied by considerable stigma. ${ }^{43}$ These factors may affect the training of IMG physicians and affect their recognition of depressive syndromes while later practicing in the United States. The findings of the present study are of practical concern because IMG physicians may work more frequently in the public sector where they might treat patient populations with higher proportions of elderly and minority patients. The results may also point to the need for targeted educational initiatives for cultural/aging competency for IMG PCPs providing much-needed care for minority elderly.

This study had several limitations. First, PCPs were informed that the study purpose was to assess clinical decision-making regarding mental health issues in primary care. Thus, the clinical encounter was simplified in that PCPs already knew they would be making some type of mental health diagnosis. Therefore, the rates of depression detection are likely artificially higher across the vignettes than would be found in real-world settings in which PCPs might ascribe symptoms to medical causes. Similarly, the vignettes were 5 minutes long. Some PCPs commented that they never would have asked so many questions related to a mental health condition. Nevertheless, although these concerns may have increased the overall detection of depression diagnoses, they were present in all vignettes. Thus, it is unlikely that they affected the main study questions of the effects of race/sex. Additionally, the PCPs in this study were drawn from a family physician sample. As a group, family physicians may be more acculturated to mental health issues than internists, and therefore their rates of depression diagnosis and treatment may be higher than found in samples of other PCPs. The latter may affect the generalizability of the results to all PCPs. Second, even though the vignettes were meticulously standardized and piloted, it is possible that subtle differences between actors' appearances or nonverbal communication might have affected the results. The piloting process and focus work with psychiatrists did not demonstrate such differences among the vignettes, but it is not known whether the survey instrument correlates with actual PCP decision-making. Several published studies support the use of case vignettes to assess clinical decisionmaking by physicians, ${ }^{44-49}$ and video (rather than written) vignettes may enhance the accuracy of such physician decisions. ${ }^{49}$ Such techniques also permit a degree of control unattainable in observational studies, allowing determination of the influence of nonmedical factors on physician decision-making. ${ }^{50}$ However, PCP interviewing skills and rapport building remain untested with the use of video patients, and these skills may be particularly important when assessing the presence of depression in minority patients and men. Third, PCPs were recruited at a national meeting, which may have resulted in a nonrepresentative sample. PCPs who attend such meetings and volunteered for the study may be more attuned to the culturally sensitive diagnosis of major depression than those who do not.

These limitations notwithstanding, the finding of similar rates of major depression diagnoses regardless of race or sex in elderly people using a standardized patient video vignette represents a step toward understanding the role of the physician in racial differences in late-life depression diagnosis and treatment in primary care settings. Although earlier studies show clear differences between races for rates of depression diagnoses, the present findings indicate that 
physician bias based simply on apparent patient race is not a likely explanation.

\section{ACKNOWLEDGMENTS}

We thank Susan M. Maixner, MD, and Barbara A. Kamholz, MD, for their assistance with the written script and Kevin A. Schulman, MD, for helpful discussions during the study's inception.

\section{REFERENCES}

1. Unutzer J. Diagnosis and treatment of older adults with depression in primary care. Biol Psychiatry 2002;52:285-292.

2. Young AS, Klap R, Sherbourne CD et al. The quality of care for depressive and anxiety disorders in the United States. Arch Gen Psychiatry 2001;58:55-61.

3. Unutzer J, Simon G, Belin TR et al. Care for depression in HMO patients aged 65 and older. J Am Geriatr Soc 2000;48:871-878.

4. Coyne J, Katz I. Improving the primary care treatment of late life depression. Med Care 2001;39:756-759.

5. Gallo JJ, Rabins PV, Iliffe S. The 'research magnificent' in late-life: Psychiatric epidemiology and the primary health care of older adults. Int J Psychiatry Med 1997;27:185-204.

6. Adebimpe VR, Hedlund JL, Cho DW et al. Symptomatology of depression in black and white patients. J Natl Med Assoc 1982;74:185-190.

7. Strakowski SM, Lonczak HS, Sax KW et al. The effects of race on diagnosis and disposition from a psychiatric emergency service. J Clin Psychiatry 1995;56:101-107.

8. Jones BE, Gray BA. Problems in diagnosing schizophrenia and affective disorders among blacks. Hosp Community Psychiatry 1986;37:61-65.

9. Strakowski SM, Shelton RC, Kolbrener ML. The effects of race and comorbidity on clinical diagnosis in patients with psychosis. J Clin Psychiatry 1993; 54:96-102.

10. Bell CC, Mehta H. The misdiagnosis of black patients with manic-depressive illness. J Natl Med Assoc 1980;72:141-145.

11. Mulsant BH, Stergiou A, Keshavan MS et al. Schizophrenia in late life: Elderly patients admitted to an acute care psychiatric hospital. Schizophr Bull 1993;19:709-721.

12. Fabrega H, Mulsant BH, Rifai AH et al. Ethnicity and psychopathology in an aging hospital-based population. J Nerv Ment Dis 1994;182:136-144.

13. Leo RJ, Narayan DA, Sherry C et al. Geropsychiatric consultation for African American and Caucasian patients. Gen Hosp Psychiatry 1997;19:216-222.

14. Kales HC, Blow FC, Bingham CR et al. Race and inpatient psychiatric diagnoses among elderly veterans. Psychiatr Serv 2000;51:795-800.

15. Blazer DG, Hybels CF, Simonsick EM et al. Marked differences in antidepressant use by race in an elderly community sample: 1986-96. Am J Psychiatry 2000;157:1089-1094.

16. Pingitore D, Snowden L, Sansone RA et al. Persons with depressive symptoms and the treatments they receive: A comparison of primary care physicians and psychiatrists. Int J Psychiatry Med 2001;31:41-60.

17. Rollman BL, Hanusa BH, Belnap BH et al. Race, quality of depression care and recovery from major depression in a primary care setting. Gen Hosp Psychiatry 2002;24:381-390.

18. Cooper LA, Gonzales JJ, Gallo JJ et al. The acceptability of treatment for depression among African-American, Hispanic and white primary care patients. Med Care 2003;41:479-489.

19. Crawford MJ, Prince M, Menezes $P$ et al. The recognition and treatment of depression in older people in primary care. Int J Geriatr Psychiatry 1998;13: $172-176$

20. Freund KM, Moskowitz MA, Lin TH et al. Early antidepressant therapy for elderly patients. Am J Med 2003;114:15-19.

21. Garb HN. Race bias, social class bias, and gender bias in clinical judgment. Clin Psychol Sci Prac 1997;4:99-120.

22. Smedley BD, Stith AY, Nelson AR. Unequal Treatment. Confronting Racial and Ethnic Disparities in Health Care. Washington, DC: National Academies Press, 2002.

23. Coleman D, Baker FM. Misdiagnosis of schizophrenia among older black veterans. J Nerv Ment Dis 1994;182:527-528.

24. Baker FM. Misdiagnosis among older psychiatric patients. J Natl Med Assoc $1995 ; 87: 872-876$.
25. Snowden LR. Bias in mental health assessment and intervention. Theory and evidence. Am J Public Health 2003;93:239-243.

26. Neighbors HW, Trierweiler SJ, Ford BC et al. Racial differences in DSM diagnosis using a semi-structured instrument: The importance of clinical judgment in the diagnosis of African Americans. J Health Soc Behav 2003;44: 237-256.

27. Glazer WM, Morgenstern H, Doucette J. Race and tardive dyskinesia among outpatients at a CMHC. Hosp Community Psychiatry 1994;45:38-42.

28. Mental Health: Culture, Race and Ethnicity-A Supplement to Mental Health. A Report of the Surgeon General. Rockville, MD: U.S. Department of Health and Human Services, Substance Abuse, and Mental Health Services. Center for Mental Health Services, 2001.

29. Schulman KA, Berlin JA, Harless W et al. The effect of race and sex on physicians' recommendations for cardiac catheterization. N Engl J Med 1999;340: 618-626.

30. Diagnostic and Statistical Manual of Mental Disorders, 4th Ed. Washington, DC: American Psychiatric Association, 1994.

31. vanRyn M, Fu SS. Paved with good intention: Do public health and human service providers contribute to racial/ethnic disparities in health? Am J Public Health 2003;93:248-255.

32. Cohen J. Quantitative methods in psychology: A power primer. Psychol Bull 1992;112:155-159.

33. Husaini BA, Moore ST. Arthritis disability, depression, and life satisfaction among black elderly people. Health Soc Work 1990;25:253-260.

34. Neighbors HW, Jackson JS. The use of informal and formal help: Four patterns of illness behavior in the black community. Am J Community Psychol 1984; 12:629-644.

35. Neighbors HW, Musick MA, Williams DR. The African American minister as a source of help for serious personal crise: Bridge or barrier to mental health care? Health Educ Behav 1998:25:759-777.

36. Miranda J, Cooper LA. Disparities in care for depression among primary care patients. J Gen Intern Med 2004;19:120-126.

37. Mojtabai R, Olfson M, Mechanic D. Perceived need and help-seeking in adults with mood, anxiety or substance use disorders. Arch Gen Psychiatry 2002; 59:77-84.

38. Yokopenic PA, Clark VA, Aneshensel CS. Depression, problem recognition and professional consultation. J Nerv Ment Dis 1983;171:15-23.

39. Sleath B, Rubin RH. Gender, ethnicity and physician-patient communication about depression and anxiety in primary care. Patient Educ Couns 2002;48: 243-252.

40. Cooper-Patrick L, Gallo J, Gonzales J et al. Race, gender, and partnership in the patient-physician relationship. JAMA 1999;282:583-589.

41. Schwartzberg JG, Guttman R. Effect of training on physician attitudes and practices in home and community care of the elderly. Arch Fam Med 1997;6: 439-444.

42. Arean PA, Alvidrez J, Feldman $M$ et al. The role of provider attitudes in prescribing antidepressants to older adults: Leverage points for effective provider education. Int J Psychiatry Med 2003;33:241-256.

43. Demyttenaere K, Bruffaerts R, Posada-Villa J et al. Prevalence, severity, and unmet need for treatment of mental disorders in the World Health Organization World Mental Health Surveys. JAMA 2004;291:2581-2590.

44. Wigton RJ, Poses RM, Collins $M$ et al. Teaching old dogs new tricks: Using cognitive feedback to improve physicians' diagnostic judgments on simulated cases. Acad Med 1990;65:S5-S6.

45. Jones TV, Gerrity MS, Earp JA. Written case simulation: Do they predict physician's behavior? J Clin Epidemiol 1990;43:805-815.

46. Kirwan JR, Chaput de Saintonge DM, Joyce CRB et al. Clinical judgment in rheumatoid arthritis. I. Rheumatologists' opinion and the development of paper patients. Ann Rheum Dis 1983;42:644-647.

47. Kirwan JR, Bellamy N, Condon $\mathrm{H}$ et al. Judging 'current disease activity' in rheumatoid arthritis - an international comparison. J Rheumatol 1983;10: 901-905.

48. Peabody JW, Luck J, Glassman P et al. Comparison of vignettes, standardized patients, and chart abstraction. A prospective validation study of 3 methods for measuring quality. JAMA 2000;283:1715-1722.

49. McNutt RA, O’Meara JJ, de Bliek R. The effect of visual information and order of patient presentation on the accuracy of physicians' estimates of acute ischemic heart disease: A pilot study. Med Decis Making 1992;12:342.

50. Feldman HA, McKinlay JB, Potter DA et al. Nonmedical influences on medical decision making: An experimental technique using videotapes, factorial design, and survey sampling. Health Serv Res 1997;32:343-366. 